\title{
The effect of fracture aperture and flow rate ratios on two-phase flow in smooth-walled single fracture
}

\author{
A. A. Alturki • B. B. Maini • I. D. Gates
}

Received: 14 November 2011 / Accepted: 2 December 2012/Published online: 4 January 2013

(C) The Author(s) 2012. This article is published with open access at Springerlink.com

\begin{abstract}
This work experimentally examines the cocurrent flow of oil and water in moderately oil-wet smoothwalled single fractures. The focus of our investigation is on studying the effects of varying fracture aperture and flow rate ratios on relative permeability to oil and water. The phase distribution and flow regimes within the fracture were closely monitored and found to vary with the flow rate ratio and total flow rate, and appeared to have a direct impact on the relative permeability. Experimental relative permeability data exhibited variations in shape indicating the effects of fracture aperture and flow ratios. Also, the data show the effects of oil-water phase interference, and phase saturation changes on the relative permeabilities for each fracture configuration. A couple of two-phase relative permeability models, namely, viscous coupling model, and homogenous single-phase approach, were tested against the experimental relative permeability data. This work provides insight into the nature of two-phase flow in a single fracture and could help in better modeling of more complex fracture networks.
\end{abstract}

Keywords Smooth-walled fracture $\cdot$ Hele-shaw . Fracture aperture $\cdot$ Flow rate ratios $\cdot$ Two-phase flow

\section{List of symbols \\ $Q \quad$ Flow rate $\left(\mathrm{m}^{3} / \mathrm{s}\right)$ \\ $\mu \quad$ Dynamic viscosity (Pa s) \\ $L \quad$ Length of test section (m) \\ $p \quad$ Pressure $(\mathrm{Pa})$}

A. A. Alturki $(\bowtie) \cdot$ B. B. Maini · I. D. Gates Chemical and Petroleum Engineering Department, Schulich School of Engineering, University of Calgary, 2500 University Drive NW, Calgary, AB T2N1N4, Canada

e-mail: ali.turki.2@aramco.com
$\Delta p \quad$ Pressure gradient $(\mathrm{Pa})$

$b \quad$ Fracture aperture $(\mathrm{m})$

$\pi \quad$ Fracture (pipe) perimeter (m)

A Flow cross-sectional area $\left(\mathrm{m}^{2}\right)$

$\tau_{\mathrm{w}} \quad$ Average wall sheer stress $(\mathrm{Pa})$

$\psi \quad$ Friction factor $(\mathrm{Nm})$

$V \quad$ Volumetric flux $\left(\mathrm{m}^{3} / \mathrm{s}\right)$

$\rho$ Density $\left(\mathrm{kg} / \mathrm{m}^{3}\right)$

$D_{\mathrm{h}} \quad$ Hydraulic diameter of fracture (m)

Re Reynolds number

$C$ Impedance parameter

$N \quad$ Constant

$k_{\mathrm{r}} \quad$ Relative permeability

$k$ Absolute permeability $\left(\mathrm{m}^{2}\right)$

$W \quad$ Hele-Shaw Cell's width (m)

\section{Subscripts}

g Gas phase

1 Liquid

m Mixture

o Oil phase

w Water phase

\section{Introduction}

In carbonate reservoirs, a rock fracture is a planar-shaped void filled with oil, water, gas, and even rock fines. Fractures, defined as a discontinuity that results from stresses that exceed the rupture strength of the rock (Aguilera 1995), span from micron-scale micro-fractures to largescale faults. Fractures co-exist with other fractures forming fracture networks. In the context of oil-bearing fractured rock reservoirs, fractures are often highly permeable flow pathways that may dominate fluid flow within the reservoir 
and production to the surface. Multiphase flow in fractures is complex. The interfaces between the phases evolve and respond to the fracture's walls and the driving forces that motivate flow, e.g. gravity drainage or pressure drive. For this reason, studies of multiphase flow in fractures are limited and the majority of studies focus on flow in single fractures.

\section{Literature review}

Depending on the relative flow rates of gas and water, Fourar et al. (1993) observed moving flow structures in which one phase formed a continuous path through the other phase. They also found that the experimental relative permeabilities of each phase are not linearly dependent on saturation. The best fit obtained was by using the homogenous single-phase model where all fluid properties were averaged. A correlation between the friction factor and average Reynolds number was used to history match and predict the pressure drop. However, Diomampo (2001) did not get satisfactory representation of nitrogen-water flow in fractures using the equivalent homogenous single-phase approach. Also, similar flow structures were observed on both the smooth- and rough-walled fractures; which differ from the flow structures suggested by Fourar and Bories (1995). Chen and Horne (2004), and Chen (2005) found that the flow structures of gas and water flow in roughwalled fracture is more scattered and tortuous compared to the ones observed with the smooth-walled fracture. Also, they observed phase trapping of gas and water due to fracture aperture variations and to capillary pressure effects. Steam and water flow in smooth-walled fracture demonstrated multiple unstable flow patterns; whereas in nitrogen and water system, each phase tends to form its own flow path with blocking and unblocking by the other phase. However, with both flow systems in rough-walled fracture, the flow structure is complex and more likely resembles flow in naturally fractured media. It exhibited capillary pressure effects and flow path tortuosity affecting phase trapping and, consequently, relative permeability. Viscous coupling model (VCM) fitted the relative permeabilities to nitrogen and water for both smooth- and roughwalled fractures. However, a similar fit was obtained for steam-water system for the smooth-walled fracture but not for the rough-walled fracture. Chen and Horne (2006) defined channel tortuosity to quantify the flow paths created by each phase in rough-walled fractures. They found that the magnitude of the flow channel tortuosity increases when the heterogeneity of the fracture increases.

The research work of Pan et al. (1996) and Shad et al. $(2009,2010)$ have examined relative permeability of liquid-liquid (namely, oil-water) two-phase flow in smooth- and rough-walled fractures as well as flow regimes and flow structures. Pan et al. (1996) found that the flow patterns in the fracture vary with variation in oil and water flow rates. Also, the discontinuous phase can still flow in smooth-walled fracture unlike the case with the granular porous media. More significant phase interference was observed when the fluids flowing in the fracture are segregated (not mixed). Finally, the single-phase homogenous model fitted their experimental data reasonably well. Pan (1999) observed four major flow structures in the smoothwalled fractures: channel, dispersed, mixed flow, stratified flow structures. However, with the rough-walled model with smaller fracture aperture $(0.26 \mathrm{~mm})$, only dispersed flow was observed. He found that relative permeability to oil is a function of oil saturation, viscosity ratio, and flow pattern, whereas, relative permeability to water is a strong function of water saturation. The effects of surface roughness on relative permeability to oil and water were more pronounced for smaller fracture aperture and at higher pressure gradient, i.e., the relative permeabilities and flow patterns observed in the rough-walled fracture with larger aperture were similar to the ones observed with the smooth-walled fracture. Shad (2009) found that when the non-wetting phase (water) flows in the form of discontinuous drops, its velocity depends on the conveying phase velocity (oil), length of the drop, viscosity ratio, capillary number, and the fracture aperture. Due to lubrication effects, he obtained relative permeability data that was often greater than unity and none of the $X$-Curve, Corey, or the VCMs were able to fit and/or predict the flow behavior. However, Shad and Gates (2010) were able to provide a reasonable analytical model, which somewhat overestimated the relative permeability to oil and underestimated the relative permeability to water.

\section{Experimental setup and procedure}

\section{Fluid properties}

Mineral oil (Imperial Oil, MARCOL-7) is used as the wetting phase in the fracture model. Table 1 lists the relevant properties of Marcol-7. Degassed-deionized dyed water was used as the non-wetting phase. Water-based super-red food coloring (Chefmaster Airbrush ColorSuper Red) was used to dye the water for better visualization and distinction between the colorless mineral oil and the water. Table 2 lists the relevant properties of the water used in the experiments. The viscosity of oil was 20 times higher than that of water at room temperature, and the oil density was $15 \%$ less than that of water. The contact angle of oil-water interface is $84^{\circ}$. The contact angle measurements were taken under oil-advancing conditions. 
Table 1 Oil (MARCOL 7) properties

\begin{tabular}{lll}
\hline Property & Value & Unit \\
\hline Grade & N and N3 NF & \\
Density at $22{ }^{\circ} \mathrm{C}$ & 850 & $\mathrm{~kg} / \mathrm{m}^{3}$ \\
Viscosity at $22{ }^{\circ} \mathrm{C}$ & 21.0 & $\mathrm{mPa} \mathrm{s}$ \\
Kinematic viscosity at $40{ }^{\circ} \mathrm{C}$ & $12.8 \mathrm{E}-6$ & $\mathrm{~m}^{2} / \mathrm{s}$ \\
Reflective index & 1.466 & \\
$\sigma_{\text {ow }}$ at $22{ }^{\circ} \mathrm{C}$ & 16 & $\mathrm{mN} / \mathrm{m}$ \\
Surface tension at $22{ }^{\circ} \mathrm{C}$ & 25 & $\mathrm{mN} / \mathrm{m}$ \\
\hline
\end{tabular}

Table 2 Deionized-degassed dyed water properties

\begin{tabular}{lll}
\hline Property & Value & Unit \\
\hline Density at $15{ }^{\circ} \mathrm{C}$ & 998.78 & $\mathrm{~kg} / \mathrm{m}^{3}$ \\
Viscosity at $20{ }^{\circ} \mathrm{C}$ & 1.1080 & $\mathrm{mPa} \mathrm{s}$ \\
Kinematic viscosity at $15{ }^{\circ} \mathrm{C}$ & $1.1094 \mathrm{E}-6$ & $\mathrm{~m}^{2} / \mathrm{s}$ \\
\hline
\end{tabular}

All of the experiments were conducted at room temperature of about $22{ }^{\circ} \mathrm{C}$ and atmospheric pressure conditions. The physicochemical properties of the fluids used were constants for all of the experiments.

\section{Physical model}

The smooth-walled Hele-Shaw cell was made of two $5 \mathrm{~cm}$ thick Plexiglas plates. Teflon shim stocks with different thickness were placed between the plates as a spacer as well as sealing gasket; no O-ring seal was used. A torque of $34.0 \mathrm{Nm}$ (25 ft.lb) was applied equally on the bolts to put the plates together. Three injection and three production ports were drilled on the upper plate. The side injection ports were used to inject oil (wetting-phase) whereas the middle port was used to inject the dyed water (non-wetting phase). Two pressure taps were drilled in the bottom plate connected to the pressure transducer; the tap closer to the injection ports was connected to the "high" side of the transducer whereas the tap at the far end was connected to the "low" side of the transducer. Table 3 lists the details of the major instruments and equipment used to build the rig; and Fig. 1 shows a simplified schematic of the experimental apparatus.

\section{Experimental procedure}

A number of Teflon shim stocks with different thickness $(0.0127,0.0254$, and $0.0381 \mathrm{~cm})$ were used to study the effect of fracture aperture (gap) on relative permeability to oil and water. All experiments were carried out with the fracture in horizontal position with horizontal fluids flow. Table 4 lists the nominal fracture apertures and the oil to water flow rate ratios used to model drainage and imbibition processes. The fractures were initially saturated with the
Table 3 Details of key instruments

\begin{tabular}{ll}
\hline Instrument & Details \\
\hline $\begin{array}{l}\text { Upstream pressure } \\
\text { transducer }\end{array}$ & Honeywell ST3000 \\
$\begin{array}{c}\text { Differential pressure } \\
\text { transducer }\end{array}$ & Rosemount Instrument Ltd. Model 3015 \\
$\begin{array}{l}\text { Digital camera } \\
\text { Oil pump }\end{array}$ & Blaster scA1000-30fc, Vision Technology \\
Water pump & ISCO Model 500D Syringe Pump \\
\hline
\end{tabular}

wetting phase (oil) and in the first flow test for each aperture only the wetting phase was flowing through the fractures. Using the designed flow rates ratios for each fracture aperture, water (non-wetting phase) was introduced into the fracture and, gradually, its flow rate was increased. At a certain ratio, the water flow rate was fixed and the oil flow rate was decreased gradually. The imbibition process, where the wetting phase saturation increases, was started after the drainage measurements had been completed; the flow rate ratios traversed back to the starting two-phase flow rate ratio of 10:1; Table 4 summarizes the each process parameters.

During the flow experiments, all data were digitally recorded and visually inspected on a computer connected to the data acquisition system (LabView 2009, National Instruments). The two pressure transducers and oil and water pumps were also connected to the data acquisition system providing instant readings of pressures, flow rates, and volumes injected. Digital images of the flow patterns in the fractures were recorded using a video camera. The oil and water saturation in the fracture were calculated from the digital images being taken every $3 \mathrm{~s}$.

\section{Fracture aperture measurements}

Darcy's law for single-phase flow (Eq. 1) was used to calculate the absolute permeability and the fracture gap. Darcy's law is valid up to Reynolds number less than about 10; i.e., laminar flow. The absolute permeability can be calculated from the generalized Darcy's law of a single flowing phase as follows:

$\frac{Q}{A}=\frac{k \Delta p}{\mu L}$

where $A$ is the cross-sectional area open to flow:

$A=b W$

The fracture gap, $b$, can be related to the absolute permeability using the cubic law:

$k=\frac{b^{2}}{12}$

Combining Eqs. 1-3, we get 
Fig. 1 Schematic of the experiment setup
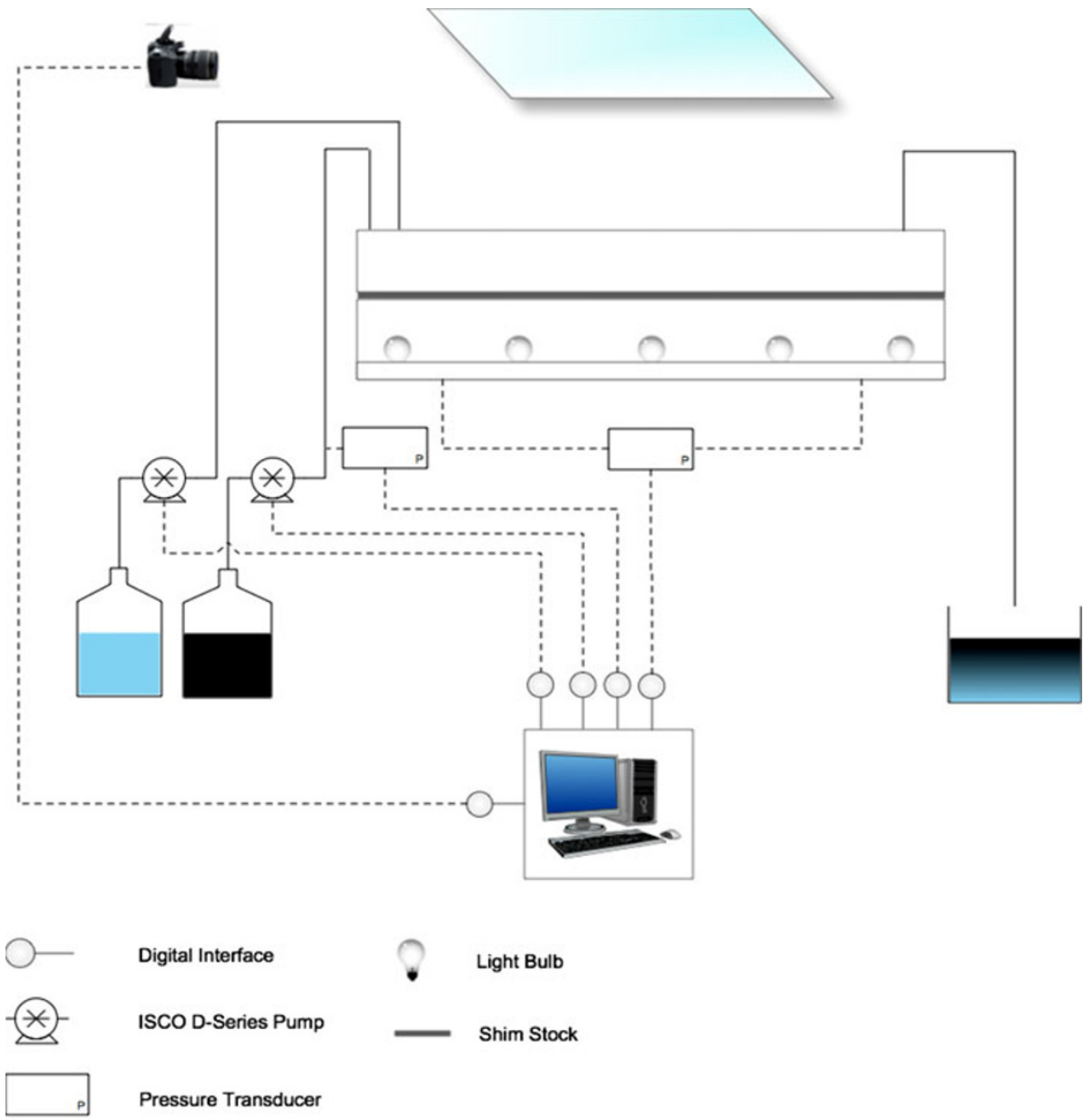

Top view of the HeleShaw Cell showing the production (right) and production (left) ports.

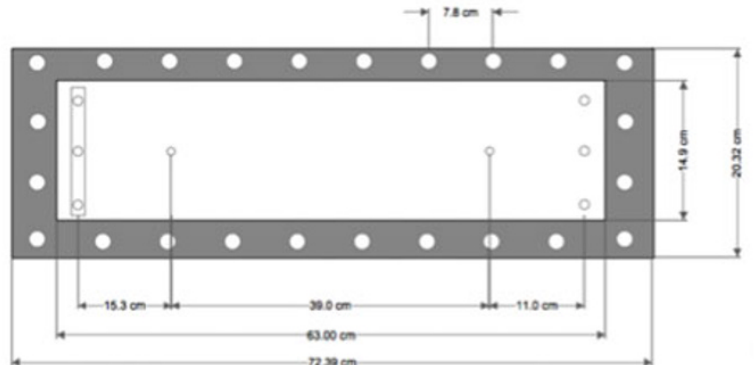

Table 4 Fracture configurations and process design

\begin{tabular}{|c|c|c|c|c|c|}
\hline \multirow{2}{*}{$\begin{array}{l}\text { Fracture } \\
\text { orientation }\end{array}$} & \multirow{2}{*}{$\begin{array}{l}\text { Nominal fracture } \\
\text { aperture }(\mathrm{cm})\end{array}$} & \multicolumn{2}{|l|}{ Process } & \multicolumn{2}{|c|}{ Oil to water flow rate ratio (ratio) } \\
\hline & & Drainage & Imbibition & $\begin{array}{l}\text { Number of } \\
\text { flow rate ratios }\end{array}$ & $\begin{array}{l}\text { Range of flow } \\
\text { rate ratios }\end{array}$ \\
\hline Horizontal & 0.0127 & $X$ & & 25 & $10: 1-1: 140$ \\
\hline Horizontal & 0.0254 & $\mathrm{X}$ & $X$ & 73 & $10: 1-1: 360-10: 1$ \\
\hline Horizontal & 0.0381 & $\mathrm{X}$ & $\mathrm{X}$ & 73 & $10: 1-1: 360-10: 1$ \\
\hline
\end{tabular}

It was found that the fracture aperture calculated with (4) Eq. 4 increased with increasing inlet fluid pressure. Note that the outlet tube was open to atmosphere. Figure 2 plots the fracture aperture (on left axis) and the product of absolute permeability $(k)$ and the cross-sectional area open to flow $(A)$ with varying differential pressure $(\Delta p)$ where $Q$ is the volumetric flow rate, $\mu$ is the viscosity, $L$ is the fracture test section length, $W$ is the fracture width open to flow, and $\Delta p$ is pressure gradient. 
Fig. 2 Hydraulic fracture aperture $(\mathrm{cm})$ and $\mathrm{KA}\left(\mathrm{m}^{4}\right)$ measurements with differential pressure (inch $\mathrm{H}_{2} \mathrm{O}$ ) for the three nominal fracture gap configurations $(0.0127,0.0254$, and $0.0381 \mathrm{~cm})$
Fig. 3 a Drainage relative permeability to oil and water in horizontal smooth-walled fracture with $0.0127,0.0254$, and $0.0381 \mathrm{~cm}$ nominal fracture apertures; b, c, $\mathbf{d}$ channel tortuosity at a given water saturation value for fracture apertures $0.0127,0.0254$, and $0.0381 \mathrm{~cm}$, respectively
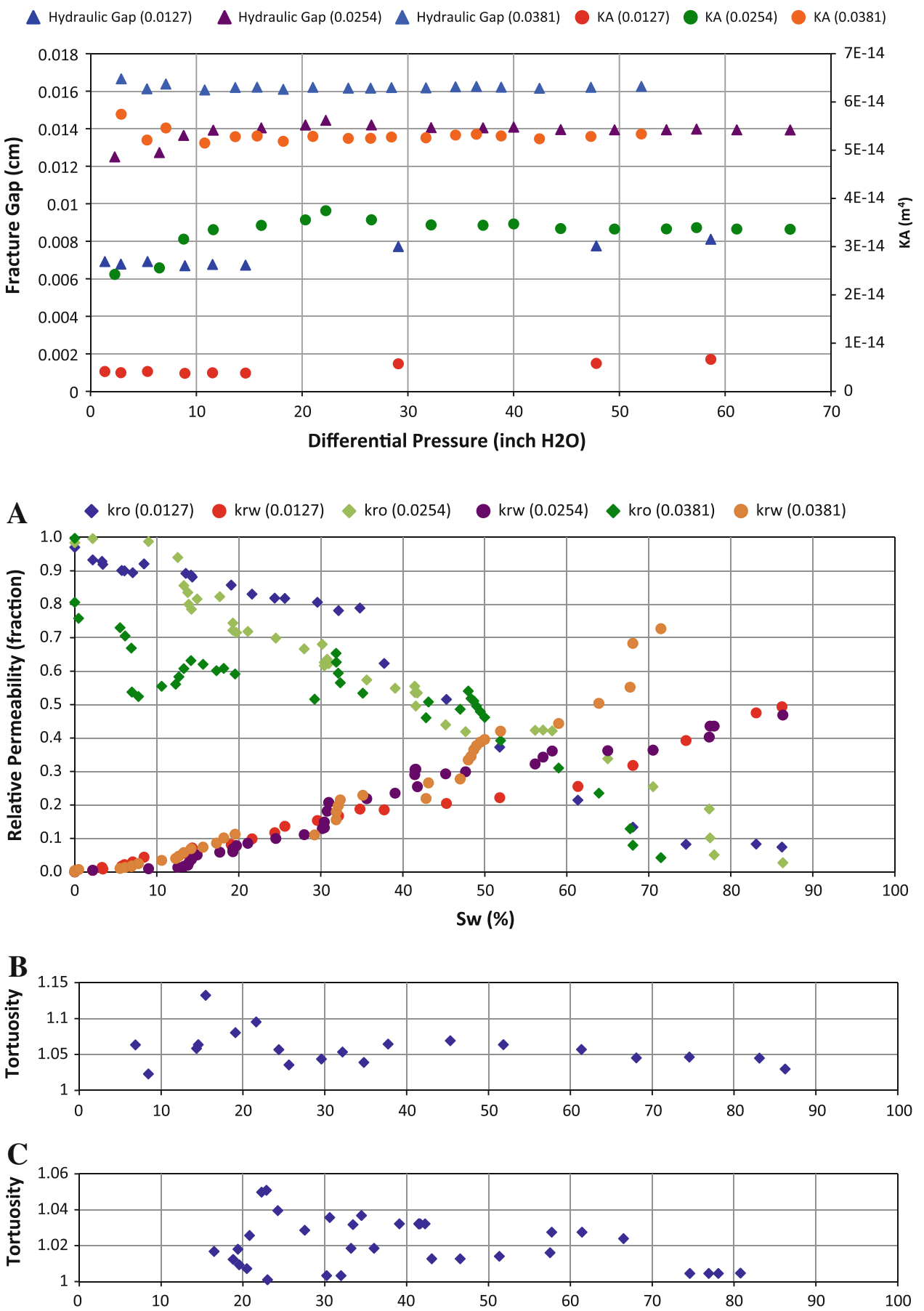

D

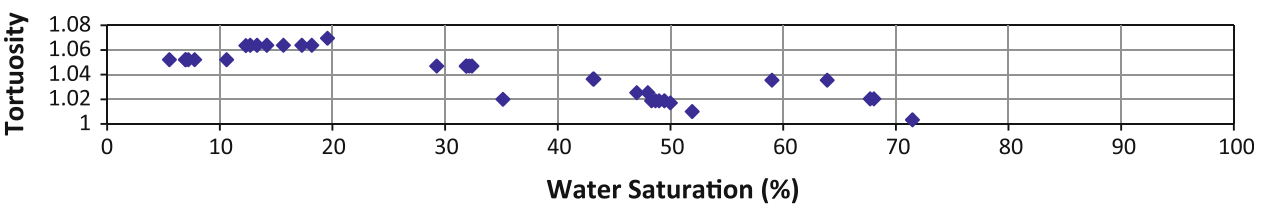

in single-phase flow at different rates. In two-phase flow tests, the average differential pressure was calculated after the completion of each experiment and then it was used to look-up the fracture aperture (to calculate the average cross-sectional area) and the average absolute permeability. This value of absolute permeability was used for calculating the relative permeability to oil and water. 
Fig. 4 a Imbibition relative permeability to oil and water in horizontal smooth-walled fracture with 0.0254 , and $0.0381 \mathrm{~cm}$ nominal fracture apertures; b, c channel tortuosity at a given water saturation value for fracture apertures 0.0254 and $0.0381 \mathrm{~cm}$, respectively
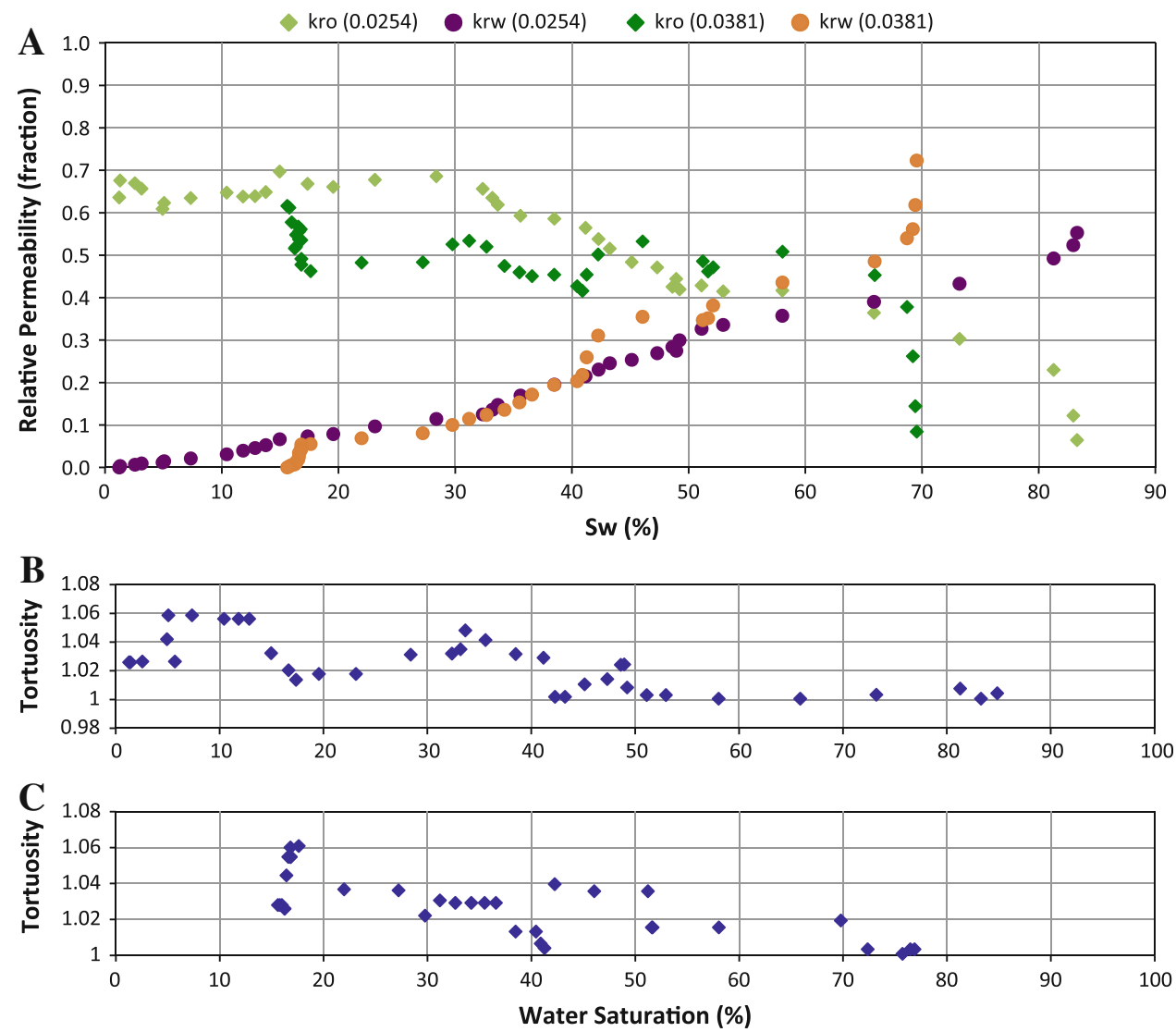

\section{Results}

Relative permeability data

The relative permeabilities to oil and water were calculated using Darcy's law. For fractures that were horizontally oriented:

$k_{\mathrm{ro}}=\frac{Q_{\mathrm{o}} \mu_{\mathrm{o}}}{A k_{\mathrm{abs}}\left(\frac{\Delta p}{L}\right)}$

and

$k_{\mathrm{rw}}=\frac{Q_{\mathrm{w}} \mu_{\mathrm{w}}}{A k_{\mathrm{abs}}\left(\frac{\Delta p}{L}\right)}$

Figures $3 \mathrm{a}$ and $4 \mathrm{a}$ show the drainage and imbibition relative permeability to oil and water, respectively, for all three fractures apertures.

Flow structures

Figure 5 shows the dominant flow structures throughout the drainage experiment for the horizontal fracture orientation with $0.0127 \mathrm{~cm}$ gap configuration. Mainly, droplet, mixed, and channel flow patterns were observed at different water saturations. At low water saturations, water droplets form and grow in size, then travels downstream. Variable droplets sizes were observed. At intermediate water saturations, a mixed flow pattern (thin channels and slugs) was observed. Somewhat more stable water channels formed at higher water saturations that were occasionally disturbed by droplets/slugs of water. Fixing the water injection flow rate and reducing the oil flow rate yielded thicker and more stable water channels; the water droplets disappeared.

Figure 6 maps the flow regimes observed with respect to the oil-water flow rates. The data points are color coded to reflect different flow regimes. The impact of flow rate ratio variations is clear on the flow regime/ structure and, consequently, on the relative permeability data.

Channel tortuosity

The channel tortuosity is calculated as follows:

$\tau=\left(L_{\mathrm{e}} / L\right)^{2}$

where $L_{\mathrm{e}}$ is the channel length and, $L$ is length of the test section between the inlet and outlet pressure taps. An average water channel tortuosity was measured by hand using the digital images. If more than one channel was formed, the 


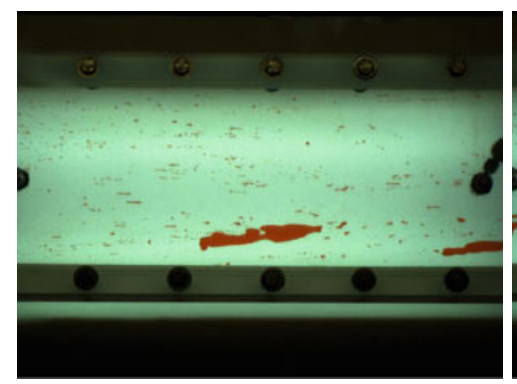

$\mathrm{Q}_{\mathrm{o}}=0.5, \mathrm{Q}_{\mathrm{w}}=0.05, \mathrm{~S}_{\mathrm{w}}=2.2$

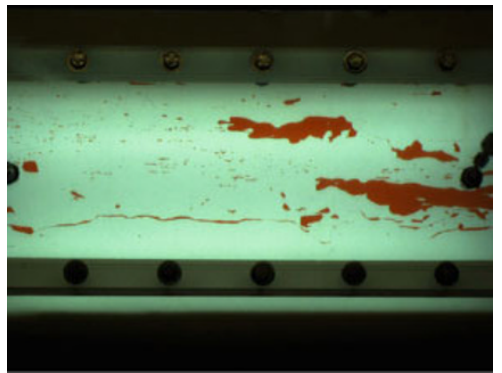

$\mathrm{Q}_{\mathrm{o}}=0.5, \mathrm{Q}_{\mathrm{w}}=0.2, \mathrm{~S}_{\mathrm{w}}=7.4$

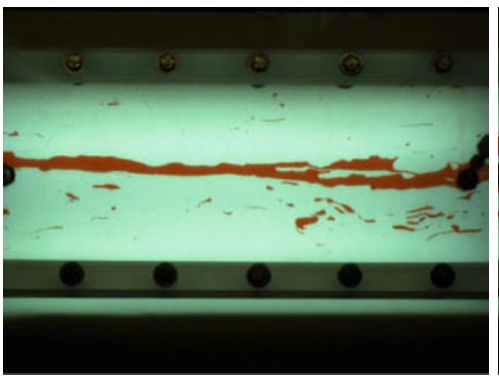

$\mathrm{Q}_{\mathrm{o}}=0.5, \mathrm{Q}_{\mathrm{w}}=0.5, \mathrm{~S}_{\mathrm{w}}=8.5$

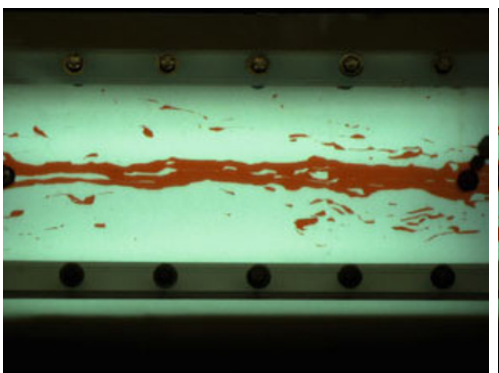

$\mathrm{Q}_{0}=0.5, \mathrm{Q}_{\mathrm{w}}=0.85, \mathrm{~S}_{\mathrm{w}}=14.3$

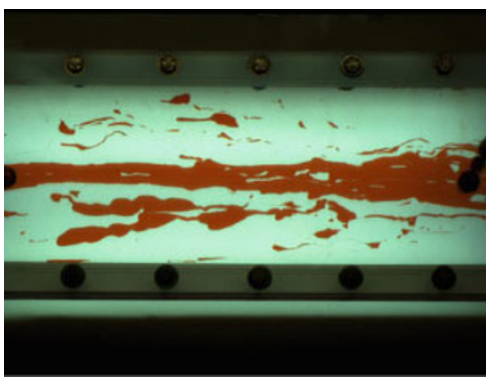

$\mathrm{Q}_{0}=0.5, \mathrm{Q}_{\mathrm{w}}=1.5, \mathrm{~S}_{\mathrm{w}}=24.4$

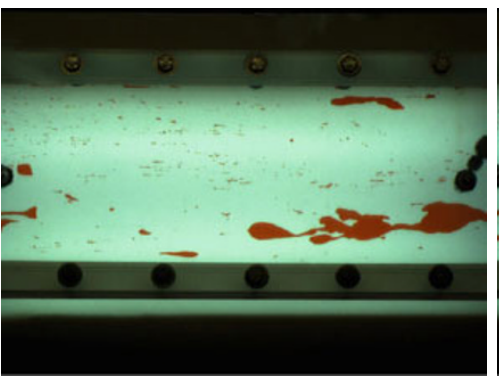

$\mathrm{Q}_{\mathrm{o}}=0.5, \mathrm{Q}_{\mathrm{w}}=0.1, \mathrm{~S}_{\mathrm{w}}=4.9$

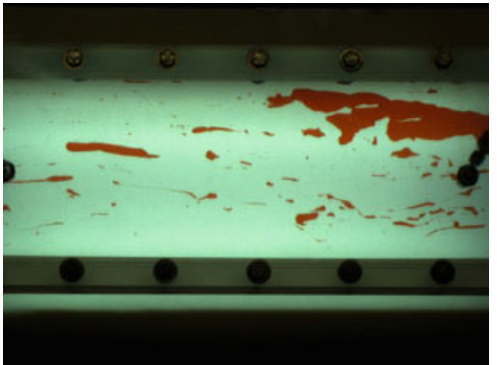

$\mathrm{Q}_{\mathrm{o}}=0.5, \mathrm{Q}_{\mathrm{w}}=0.25, \mathrm{~S}_{\mathrm{w}}=8.7$

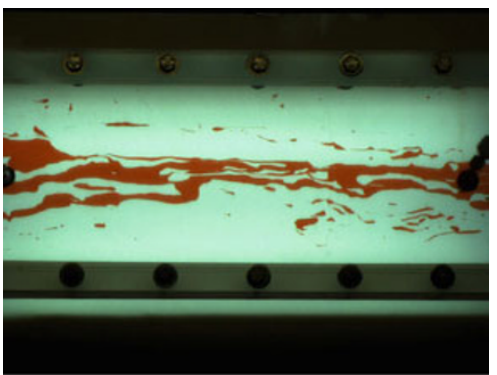

$\mathrm{Q}_{0}=0.5, \mathrm{Q}_{\mathrm{w}}=0.65, \mathrm{~S}_{\mathrm{w}}=15.4$

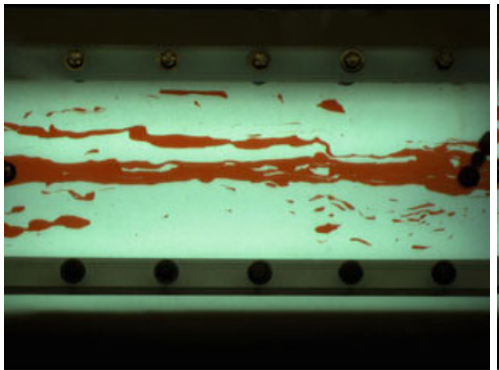

$\mathrm{Q}_{0}=0.5, \mathrm{Q}_{\mathrm{w}}=1.0, \mathrm{~S}_{\mathrm{w}}=19.1$

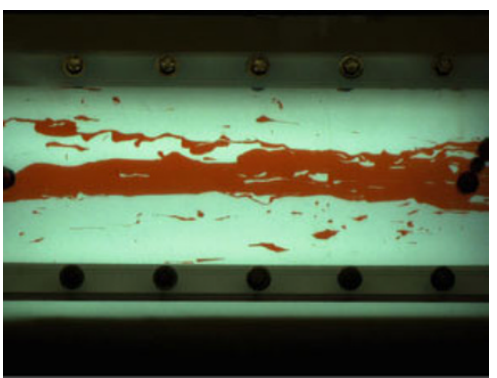

$\mathrm{Q}_{\mathrm{o}}=0.5, \mathrm{Q}_{\mathrm{w}}=1.75, \mathrm{~S}_{\mathrm{w}}=25.6$

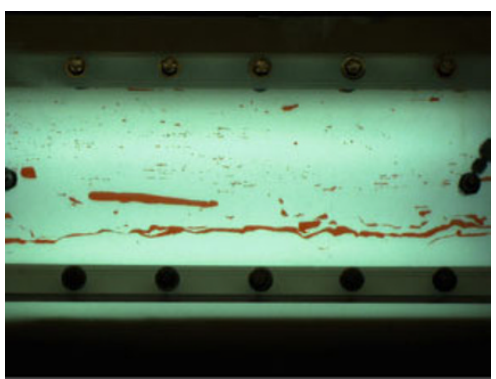

$\mathrm{Q}_{0}=0.5, \mathrm{Q}_{\mathrm{w}}=0.15, \mathrm{~S}_{\mathrm{w}}=3.3$

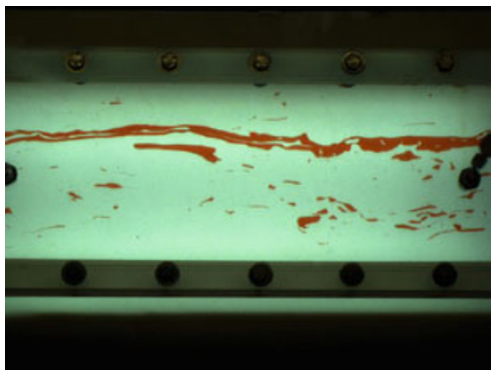

$\mathrm{Q}_{\mathrm{o}}=0.5, \mathrm{Q}_{\mathrm{w}}=0.35, \mathrm{~S}_{\mathrm{w}}=6.9$

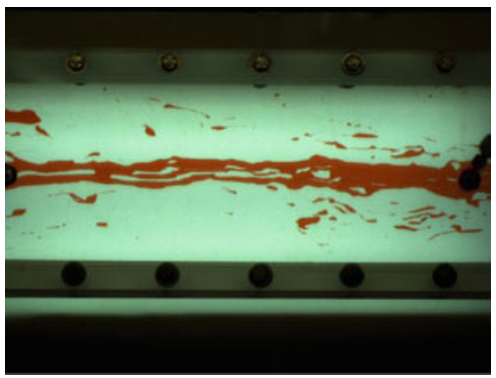

$\mathrm{Q}_{0}=0.5, \mathrm{Q}_{\mathrm{w}}=0.75, \mathrm{~S}_{\mathrm{w}}=14.5$

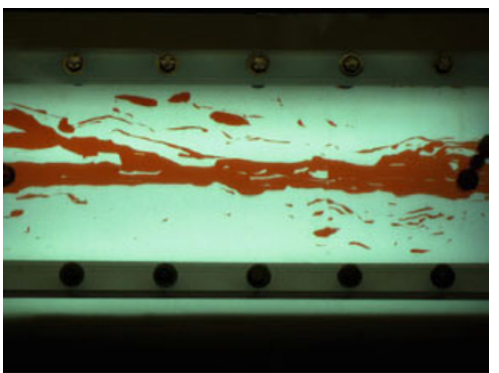

$\mathrm{Q}_{\mathrm{o}}=0.5, \mathrm{Q}_{\mathrm{w}}=1.25, \mathrm{~S}_{\mathrm{w}}=21.6$

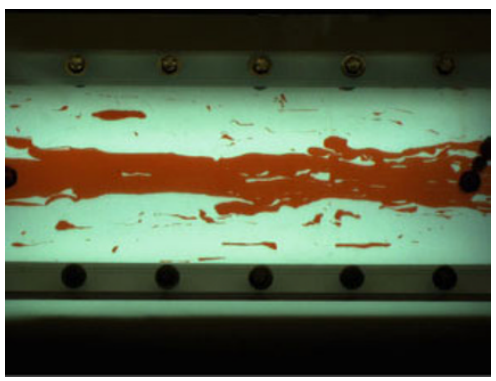

$\mathrm{Q}_{\mathrm{o}}=0.5, \mathrm{Q}_{\mathrm{w}}=2.0, \mathrm{~S}_{\mathrm{w}}=29.6$

Fig. 5 Oil-water flow structure map/regime from the smooth-walled fracture in horizontal orientation with nominal fracture gap of $0.0127 \mathrm{~cm}$ ( $Q_{\mathrm{o}}$ and $Q_{\mathrm{w}}$ are expressed in $\mathrm{ml} / \mathrm{min}$, and $S_{\mathrm{w}}$ is percentage) 


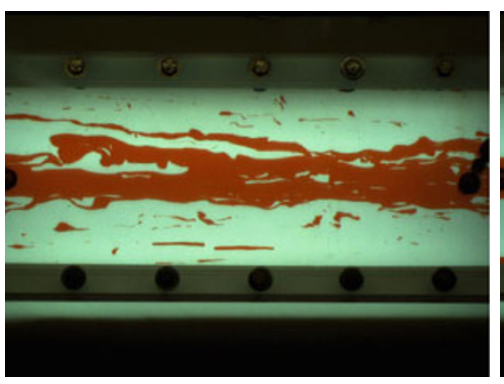

$\mathrm{Q}_{\mathrm{o}}=0.5, \mathrm{Q}_{\mathrm{w}}=2.25, \mathrm{~S}_{\mathrm{w}}=32.2$

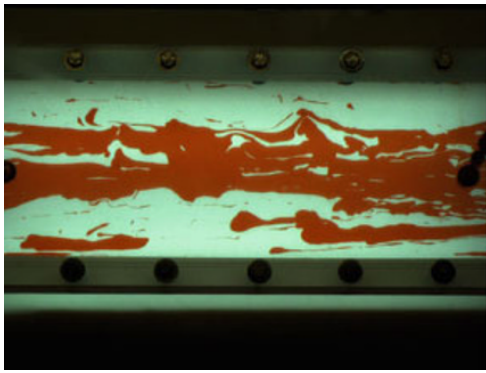

$\mathrm{Q}_{\mathrm{o}}=0.3, \mathrm{Q}_{\mathrm{w}}=2.5, \mathrm{~S}_{\mathrm{w}}=45.3$

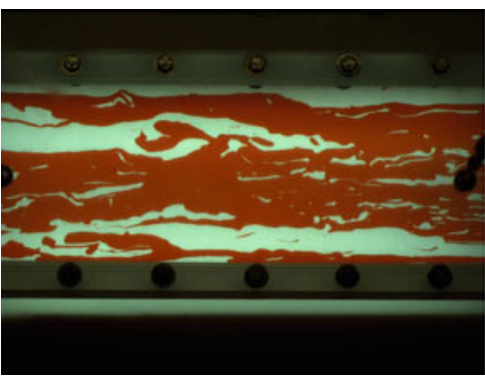

$\mathrm{Q}_{\mathrm{o}}=0.05, \mathrm{Q}_{\mathrm{w}}=2.5, \mathrm{~S}_{\mathrm{w}}=68.1$

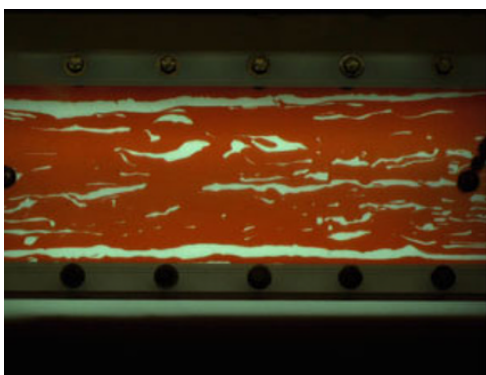

$\mathrm{Q}_{\mathrm{o}}=0.025, \mathrm{Q}_{\mathrm{w}}=3.5, \mathrm{~S}_{\mathrm{w}}=86.2$

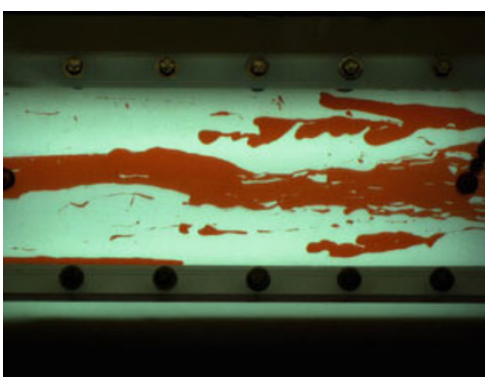

$\mathrm{Q}_{\mathrm{o}}=0.5, \mathrm{Q}_{\mathrm{w}}=2.5, \mathrm{~S}_{\mathrm{w}}=34.8$

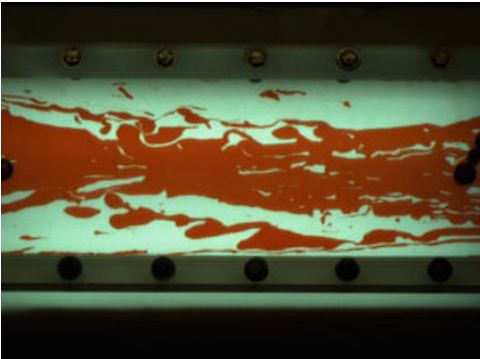

$\mathrm{Q}_{\mathrm{o}}=0.2, \mathrm{Q}_{\mathrm{w}}=2.5, \mathrm{~S}_{\mathrm{w}}=51.8$

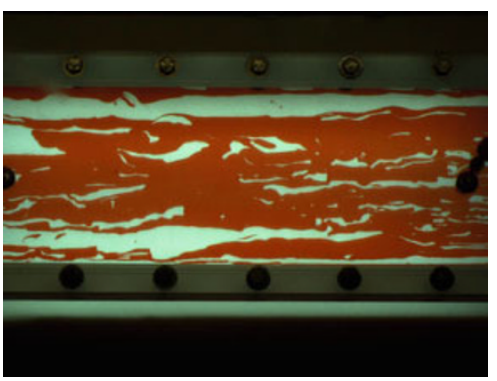

$\mathrm{Q}_{\mathrm{o}}=0.025, \mathrm{Q}_{\mathrm{w}}=2.5, \mathrm{~S}_{\mathrm{w}}=74.5$

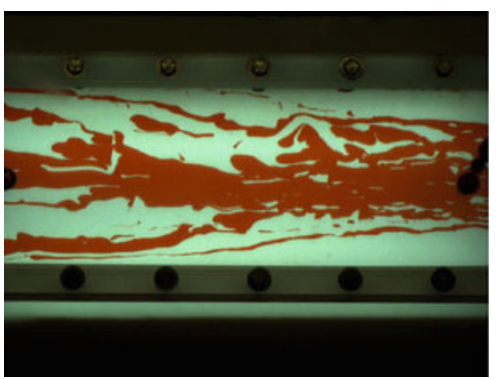

$\mathrm{Q}_{\mathrm{o}}=0.4, \mathrm{Q}_{\mathrm{w}}=2.5, \mathrm{~S}_{\mathrm{w}}=37.7$

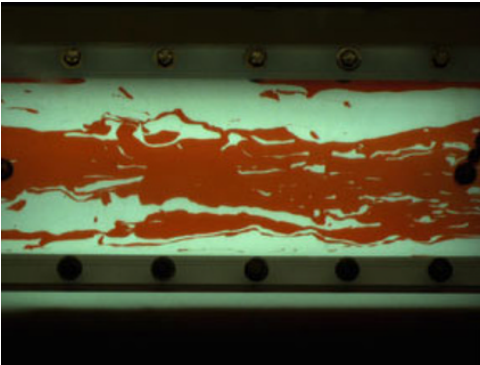

$\mathrm{Q}_{\mathrm{o}}=0.1, \mathrm{Q}_{\mathrm{w}}=2.5, \mathrm{~S}_{\mathrm{w}}=61.4$

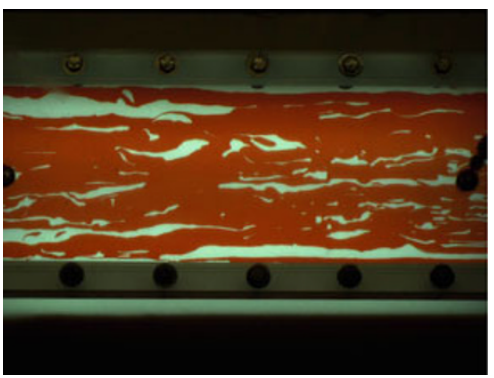

$\mathrm{Q}_{\mathrm{o}}=0.025, \mathrm{Q}_{\mathrm{w}}=3.0, \mathrm{~S}_{\mathrm{w}}=83.1$

Fig. 5 continued

Fig. 6 Oil-Water flow structure map/regime from the smooth-walled fracture in horizontal orientation with nominal fracture gap of $0.0127 \mathrm{~cm}\left(Q_{\mathrm{o}}\right.$ and $Q_{\mathrm{w}}$ are expressed in $\mathrm{ml} / \mathrm{min}$, and $S_{\mathrm{w}}$ is percentage)

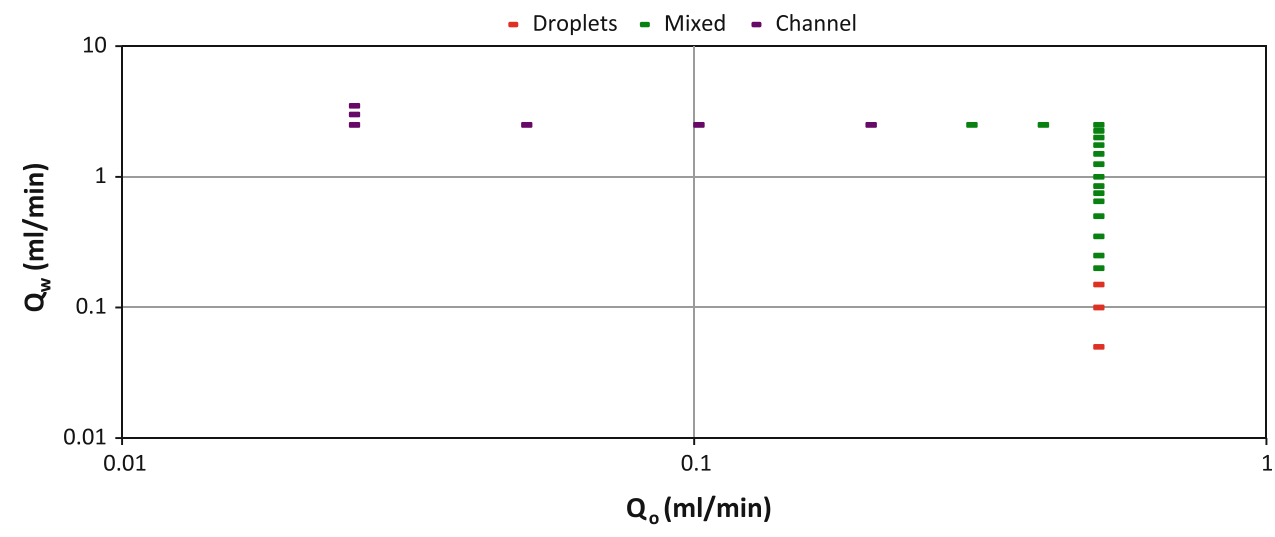


Fig. 7 a Drainage relative permeability to oil and water in horizontal smooth-walled fracture with $0.0127 \mathrm{~cm}$ nominal fracture apertures data fit with the viscous coupling model (VCM)
Fig. 8 a Drainage relative permeability to oil and water in horizontal smooth-walled fracture with $0.0254 \mathrm{~cm}$ nominal fracture apertures data fit with the viscous coupling model (VCM); b imbibition data fit with the viscous coupling model (VCM) for the same model
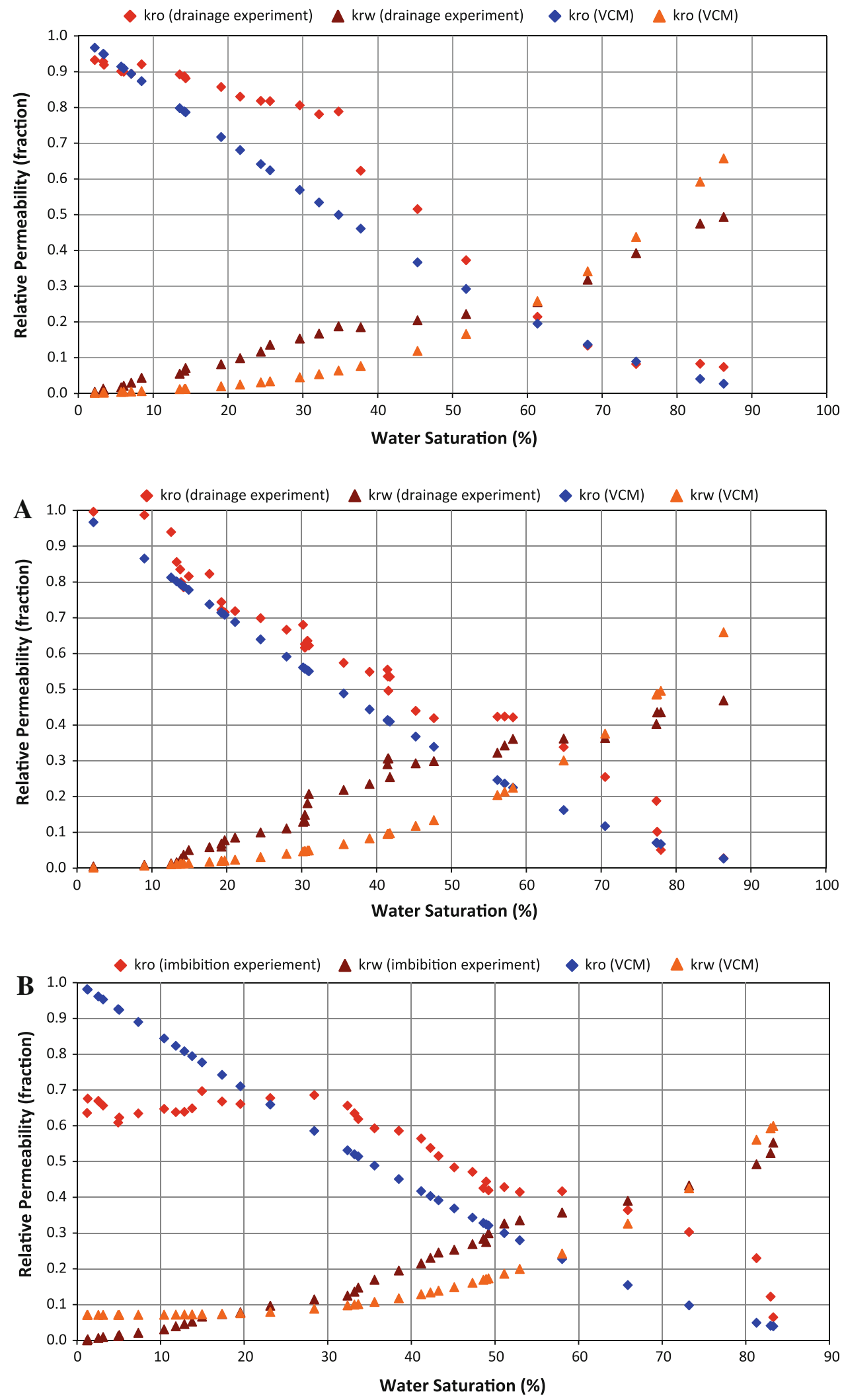

channel length was averaged. Figures 3 and 4 show the channel tortuosity at each water saturation value where the relative permeability data was calculated. Generally, the channel tortuosity data shows slightly greater than unity tortuosity values but all indicates that water channels tortuosity decreases with increasing fracture apertures. 
Fig. 9 a Drainage relative permeability to oil and water in horizontal smooth-walled fracture with $0.0381 \mathrm{~cm}$ nominal fracture apertures data fit with the viscous coupling model (VCM); b imbibition data fit with the viscous coupling model (VCM) for the same model
Fig. 10 Imbibition relative permeability to oil and water in horizontal smooth-walled fracture with $0.0127 \mathrm{~cm}$ nominal fracture apertures data fit with the homogeneous single-phase model (HSPM)
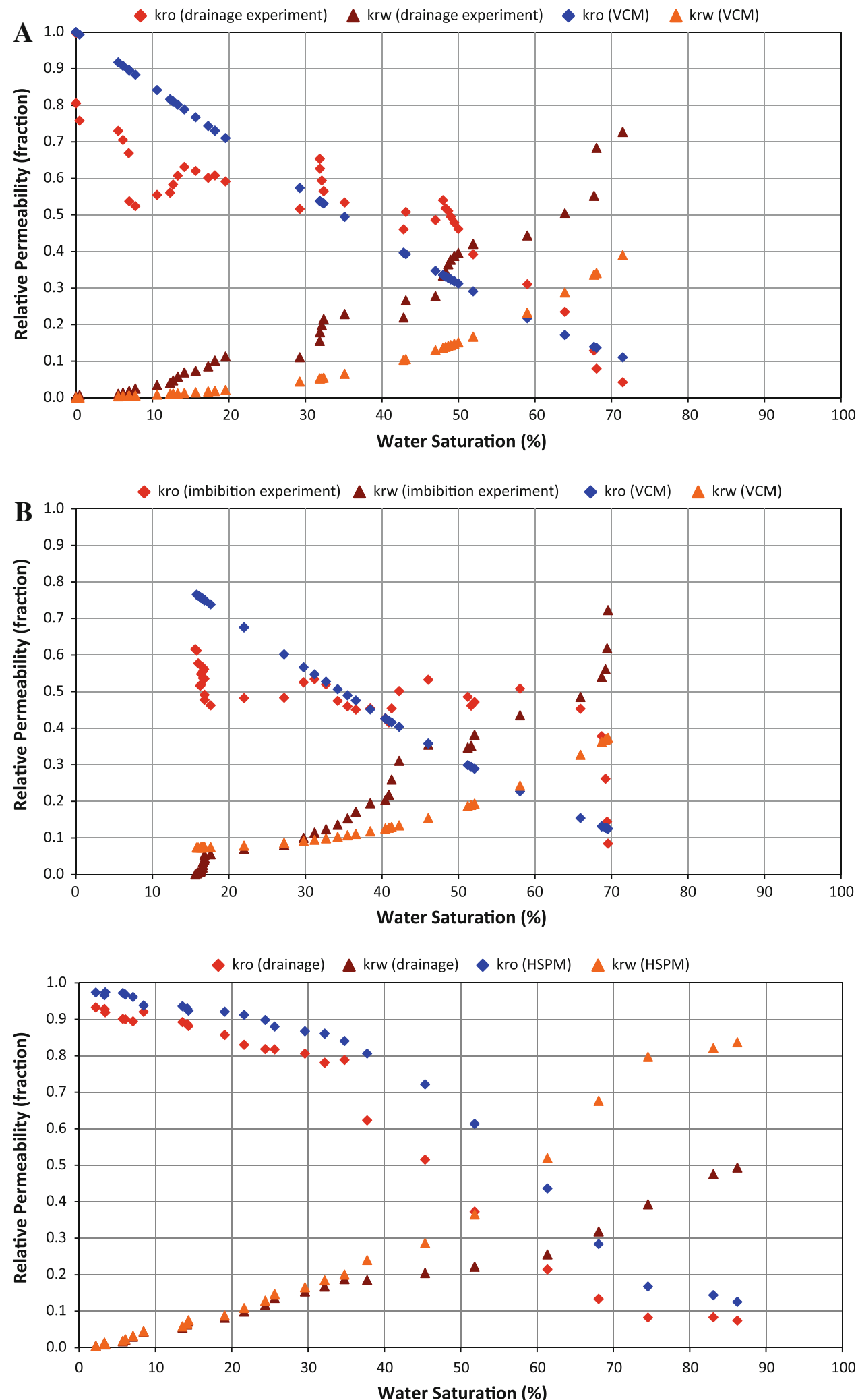

Data matching with model predictions

In an attempt to fit the experimental data, the VCM, and the homogenous single-phase model/approach (HSPM) were used. Fourar and Lenomand (1998) came up with the VCM; it was used to find the relative permeabilities of two flowing phases between parallel plates by accounting for the phases' viscosity ratio. According to 
Fig. 11 a Drainage relative permeability to oil and water in horizontal smooth-walled fracture with $0.0254 \mathrm{~cm}$ nominal fracture apertures data fit with the homogeneous single-phase model (HSPM); b imbibition data fit with the homogeneous single-phase model (HSPM) for the same model
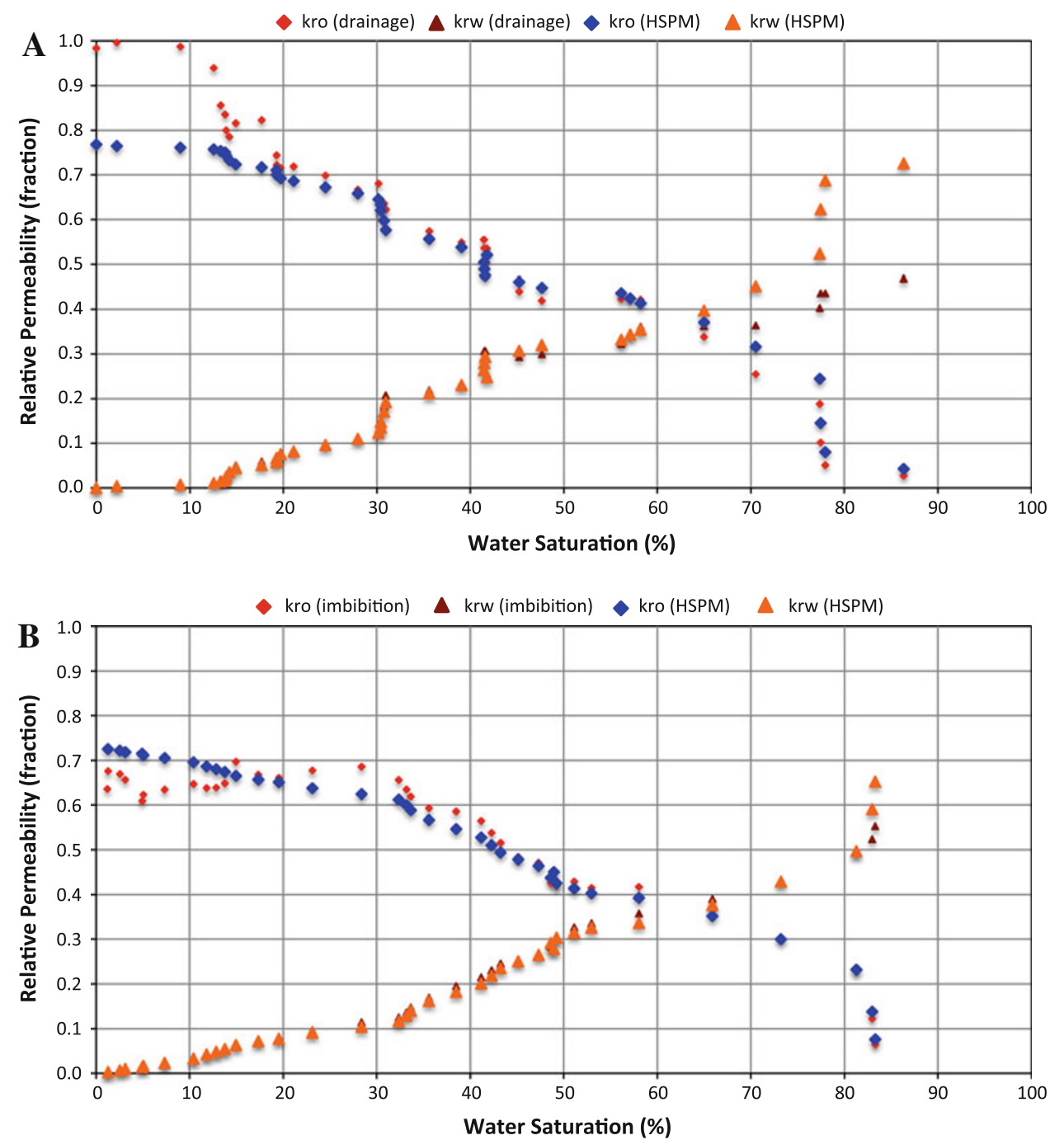

this model, the relative permeability to the wetting phase $l$ :

$k_{\mathrm{rl}}=\left(3-S_{1}\right) \frac{S_{1}^{2}}{2}$

whereas the relative permeability to the non-wetting phase g:

$k_{\mathrm{rg}}=\left(1-S_{1}\right)^{3}+\frac{3}{2} R_{\mu} S_{1}\left(2-S_{1}\right)$

The viscosity ratio, $R_{\mu}$, equals the ratio of the viscosity of the non-wetting phase ( $\mathrm{g}$ ) to that of the wetting phase (1). The VCM of Fourar and Lenomand (1998) neglects capillary pressure effects. Figures 7, 8, and 9 shows the VCM fit for the drainage and imbibition experimental data for all fracture apertures $(0.0127,0.0254$, and $0.0381 \mathrm{~cm}$, respectively).

Pan et al. (1996) used the homogenous single-phase approach to fit their experimental data, using an approach similar to that of Lockhart and Martinelli (1949) for pipe flow. In this model, for laminar flow conditions
$\left(R e_{\mathrm{m}}<1,000\right)$, the pressure gradient is proportional to the mean phase velocity, $V_{\mathrm{m}}$, and mean phase viscosity, $\mu_{\mathrm{m}}$, as shown below:

$\Delta p=-2 C \mu_{\mathrm{m}} V_{\mathrm{m}} \frac{L}{D_{\mathrm{h}}^{2}}$

where $C$ is the proportionality constant in generalized Blasius friction factor versus Reynolds number relationship (Eq. 14) and is determined from the experimental data. $L$ is the length of the test section. The mean velocity of the two phases can be calculated as follows:

$V_{\mathrm{m}}=\frac{Q_{\mathrm{o}}+Q_{\mathrm{w}}}{A}$

The viscosity of the mixture:

$\mu_{\mathrm{m}}=\frac{\mu_{\mathrm{o}} Q_{\mathrm{o}}+\mu_{\mathrm{w}} Q_{\mathrm{w}}}{Q_{\mathrm{o}}+Q_{\mathrm{w}}}$

and the hydraulic diameter of the fracture is calculated as follows: 
Fig. 12 a Drainage relative permeability to oil and water in horizontal smooth-walled fracture with $0.0381 \mathrm{~cm}$ nominal fracture apertures data fit with the homogeneous single-phase model (HSPM); b imbibition data fit with the homogeneous single-phase model (HSPM) for the same model
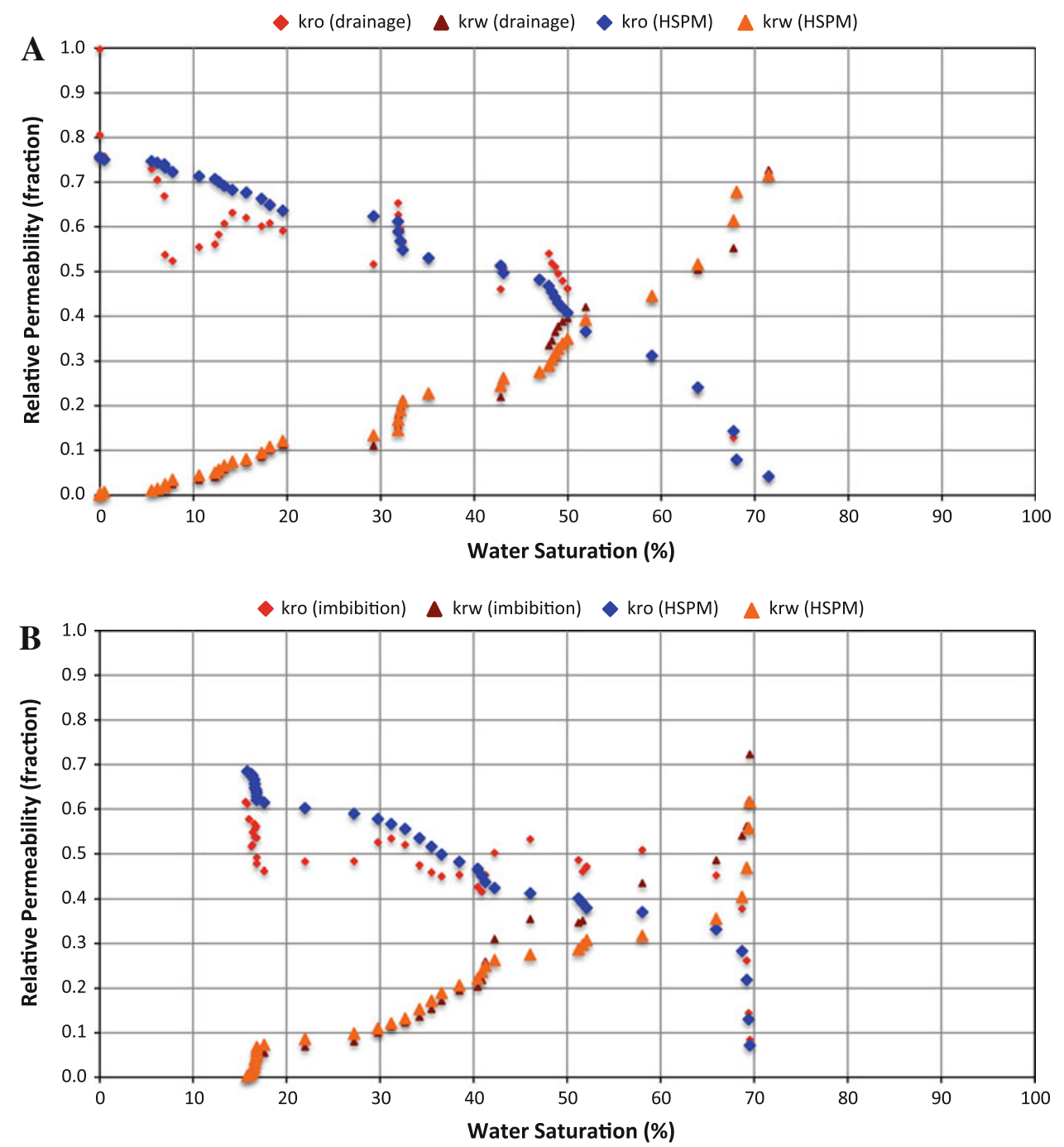

$D_{\mathrm{h}}=\frac{4 A}{P}=2 a$

where $\pi$ is the perimeter of the fracture and $A$ is crosssectional area. The friction factor and Reynolds number are calculated as follows:

$\psi=\frac{c}{R e_{\mathrm{m}}^{n}}$

$R e_{\mathrm{m}}=\frac{D_{\mathrm{h}} \rho_{\mathrm{m}} V_{\mathrm{m}}}{\mu_{\mathrm{m}}}$

Equation 10 is valid for laminar flow conditions, i.e., when $n$ in Eq. 14 is equal to 1 . The relative permeability to oil and water are calculated using Eqs. 6 and 7 with the pressure values calculated by Eq. 10 .

Figures 10, 11, and 12 depict experimental data fitting with the homogenous single-phase model for fracture apertures $0.0127,0.0254$, and $0.0381 \mathrm{~cm}$, respectively.

\section{Discussion}

In two-phase flow in smooth-walled fracture, the capillary forces play a smaller role than viscous forces, especially at larger fracture apertures and/or higher flow rates and at low saturations of either phase where the interfacial area is relatively small. This is contrary to multiphase flow in porous media where even small saturations of the nonwetting phase can impede the flow of the wetting phase.

As shown in Figs. 7, 8, and 9, the VCM fits the drainage and imbibition relative permeability to oil to reasonably well; however, it under predicts the relative permeability to water from both drainage and imbibition experiments. A better fit was obtained when using the HSPM; it fits the experimental date better than the VCM as illustrated by Figs. 10, 11, and 12. The drainage impedance parameter, $C$, values are $36.93,31.24$, and 34.88 for fracture apertures $0.0127,0.0254$, and $0.0381 \mathrm{~cm}$, respectively; whereas, the 
Fig. 13 Darcy's mixture mean velocity corrected capillary number variation with oil saturation from the drainage experiment with horizontal smooth-walled fracture with $0.0127,0.0254$, and $0.0381 \mathrm{~cm}$ nominal fracture apertures

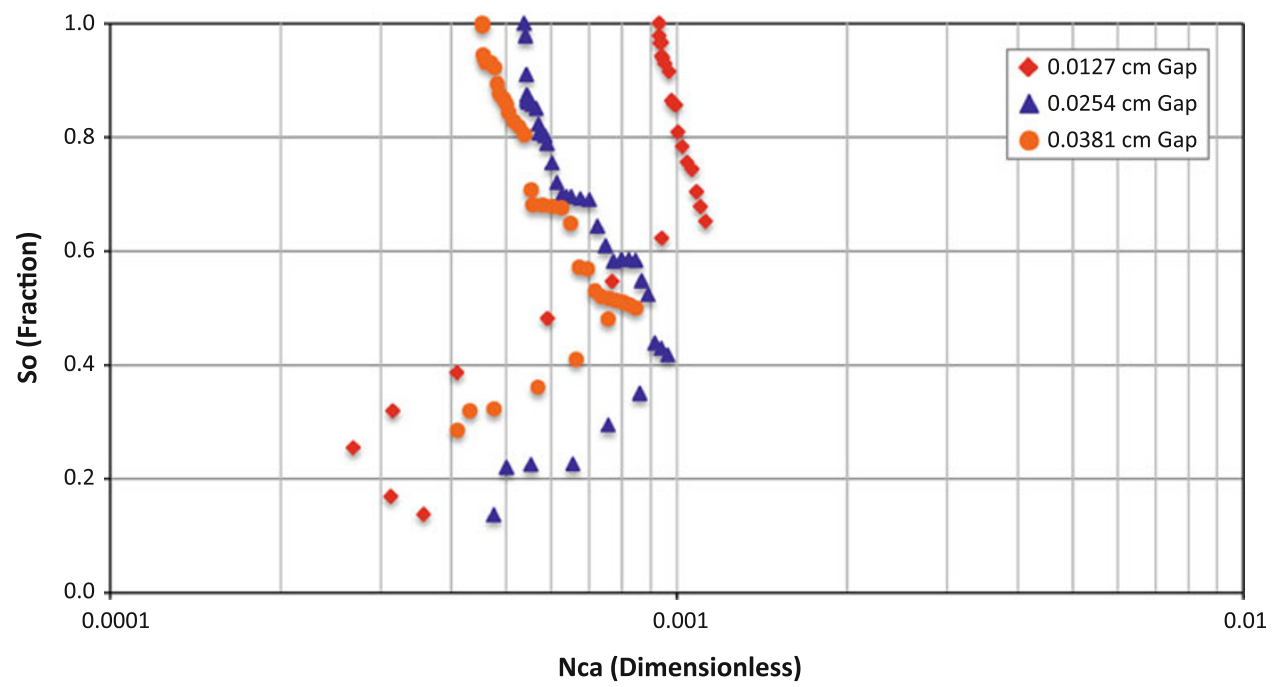

Fig. 14 Darcy's mixture mean velocity corrected capillary number variation with residual oil saturation from the imbibition experiment with horizontal smooth-walled fracture with 0.0254 and $0.0381 \mathrm{~cm}$ nominal fracture apertures

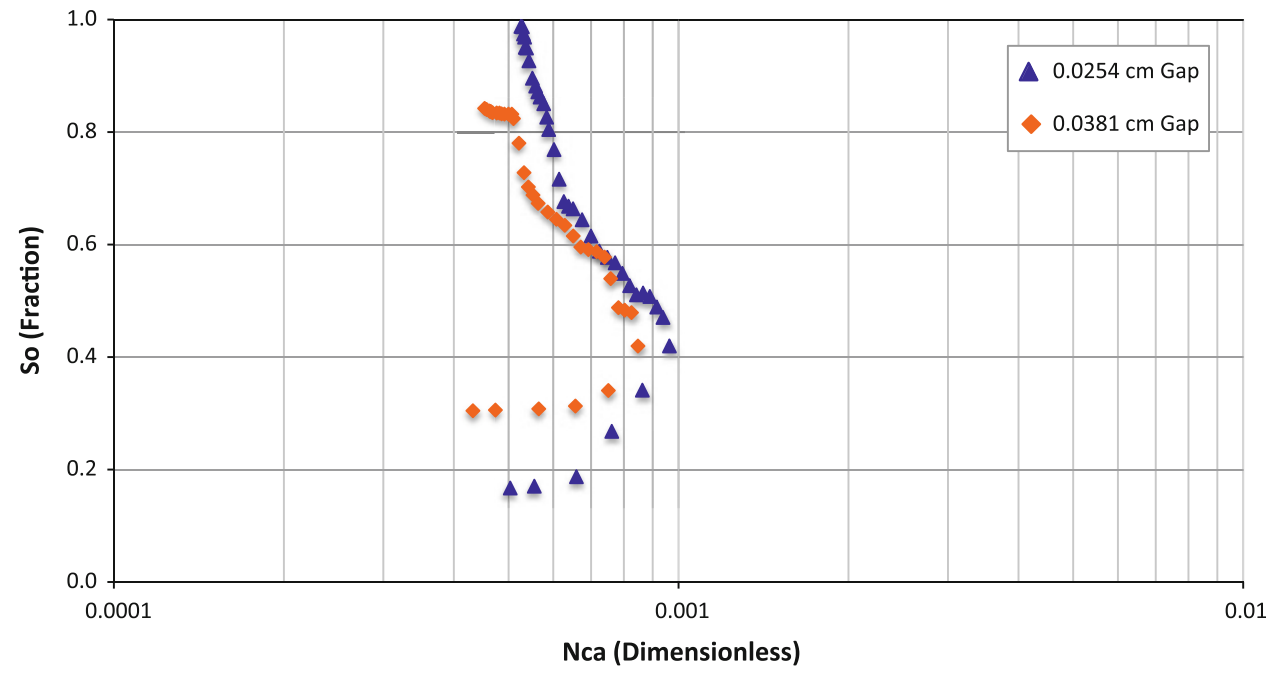

imbibition impedance parameter values are 32.93 and 31.68 for 0.0254 , and $0.0381 \mathrm{~cm}$, respectively. HSPM over predicts the relative permeability to water at higher water saturations. The results also show that that the interference between the two phases is minimal. For each fracture aperture, a friction factor parameter, $C$, was obtained. As the fracture aperture increased the corresponding $C$ decreased.

To examine the relative magnitude of viscous and capillary forces, a capillary number was calculated for each steady-state $S_{\mathrm{o}}$ value from two-phase flow; Figs. 13 and 14 show the calculated data obtained from drainage and imbibition experiments, respectively. It is defined as follows:

$N_{\mathrm{ca}}=\frac{V_{\mathrm{m}} \mu_{\mathrm{m}}}{\sigma_{\mathrm{ow}}}$

where $V_{\mathrm{m}}$ is the mean mixture velocity, $\mu_{\mathrm{m}}$ is the mixture viscosity, and $\sigma_{\text {ow }}$ is the interfacial surface tension between the two fluids (oil and water). Figure 13 shows the capillary numbers obtained from the drainage experiments for the three fracture configurations. At $40 \%$ water saturation, the capillary numbers obtained from the fracture with $0.0127 \mathrm{~cm}$ gap experiments started to decrease indicating some effect of capillary forces on the process. The high capillary numbers from the other two fracture configurations show the domination of viscous forces on the twophase flow. The imbibition capillary numbers are shown in Fig. 14. The curves are characterized by high capillary numbers and insensitivity to the change in saturation within the fracture.

\section{Conclusions}

A smooth-walled Hele-Shaw cell was used to represent the smooth-walled fracture. The fracture was horizontally oriented. Relative permeability to oil and water were 
obtained for $0.0127,0.0254$, and $0.0381 \mathrm{~cm}$ fracture apertures. The fracture aperture did not affect the relative permeability to oil; however, the relative permeability to water, slightly, increases with increasing fracture gap.

Three distinct flow structures: droplet, mixed and channel flow patterns were observed throughout the drainage process with fracture gap of $0.0127 \mathrm{~cm}$. Stable water channels were formed at higher water-oil flow rate ratios. Stable channels form earlier in the process with increasing fracture gaps.

Viscous coupling model poorly fits the drainage and imbibition relative permeability to oil whereas it fits the relative permeability to water quite well. However, better fit was obtained with the HSPM. Despite of the fact that steady-state oil saturation in two phase flow is not a direct function of capillary number, capillary numbers from this smooth-walled fractures suggest that lowest oil saturation can be attained by increasing the water to oil flow rate ratios (drainage process).

Depending on the contact angle during the drainage and imbibition processes, one notices a shift in the relative permeability curves crossing point. The smooth-walled Plexiglas exhibited mildly oil-wet to neutral wettability in all tests. Channel tortuosity did not exhibit significant increase from unity; it was expected from the smooth-walled fracture.

Acknowledgments The authors acknowledge financial support from Saudi ARAMCO, and the Department of Chemical and Petroleum engineering for facilitating the laboratory work.

Open Access This article is distributed under the terms of the Creative Commons Attribution License which permits any use, distribution, and reproduction in any medium, provided the original author(s) and the source are credited.

\section{References}

Aguilera R (1995) Naturally fractured reservoirs, 2nd edn. Pennwell, Tulsa

Chen CY (2005) Liquid-gas relative permeabilities in fractures: effects of flow structures, phase transformation and surface roughness. PhD Dissertation. Stanford University, Stanford
Chen CY, Horne RN (2004) Experimental study of liquid flow structures effects on relative permeabilities in a fracture. Water Resour Res 40: W08301. doi:10.1029/2004WR003026

Chen CY, Horne RN (2006) Two-phase flow in rough walled fractures: experiments and a flow structure model. Water Resour Res 42: W03430. doi:10.1029/2004WR003837

Diomampo GP (2001) Relative permeability through fractures. MSc Dissertation, Stanford University, Stanford

Fourar M, Bories S (1995) Experimental study of air-water two-phase flow through a fracture (narrow channel). Int $\mathbf{J}$ Multiph Flow 21(4):621-637

Fourar M, Lenomand R (1998) A viscous coupling model for relative permeabilities in fractures. SPE 49006

Fourar M et al (1993) Two-phase flow in smooth and rough fractures: measurement and correlation by porous-medium and pipe flow models. Water Resour Res 29(11):3699-3708

Lockhart RW, Martinelli RC (1949) Proposed correction of data for isothermal two-phase two-component flow in pipes. Chem Eng Prog 45:39-48

Pan X (1999) Immiscible Tow Phase Flow in a Fracture. Ph.D. Thesis, University of Calgary, Calgary, Alberta, Canada

Pan X, Wong RC, Maini BB (1996) Steady-state two-phase in a smooth parallel fracture. Paper 96-39, The Petroleum Society in Calgary, Alberta

Shad S (2009) Two-phase flow in single fracture. PhD Dissertation, University of Calgary, Calgary

Shad S et al (2009) The velocity and shape of converted elongated liquid drops in vertical narrow gaps. J Can Petrol Technol 48(12):26-31

Shad S, Gates ID (2010) Multiphase flow in fractures: co-current and counter-current flow in a fracture. $\mathrm{J}$ Can Petrol Technol 49(2):48-55

Shad S, Maini BB, Gates ID (2010) Effect of fracture and flow orientation on two-phase flow in an oil-wet fracture: relative permeability curves and flow structure. SPE 132229 